\title{
Enhanced Biochemical Activity
}

National Cancer Institute

\section{Source}

National Cancer Institute. Enhanced Biochemical Activity. NCI Thesaurus. Code C45421.

A quantitative increase in a measurable amount of a specific function or role performed by a biological entity in a biophysical process, biochemical reaction, or biochemical process compared to the level of activity exhibited by that same biological entity in the majority of healthy individuals in a reference population. 